position of such nutrient arteries is reasonably predictable.

On the nerve a series of epineural vessels is formed, whose branches pass into the perineurium and, finally, there is produced within the fasciculi a longitudinally disposed capillary plexus which is continuous throughout the length of the nerve and is not dominated by local nutrient vessels.

Experimental. The intraneural plexus forms a system which is normally reinforced by the local nutrient arteries, but which can function adequately in a given length of nerve even when the local branches are ligated.

Obliteration of epineural or intraneural vessels produces degeneration of varying degree depending on the extent of vascular deprivation.

The complete and intact system of vessels upon and more particularly within the nerve is function ally more important than any localized group of nutrient vessels.

\section{BIBLIOGRAPHY}

ADAMS, W. E. (1942), F. Anat., Lond., 76, 323

ADAMS, W. E. (1943), F. Anat., Lond., 77, 243.

ADAMS, W. E. and ROBINSON, W. (194I), Lancet, Novembe 8th, p. 555 .

ATKINSON, M. (1941), f. Amer. Med. Ass., 116, 1753.

BACSICH, P. and WYBURN, G. M. (1945), Ұ. Anat., 79, 74.

DENNY BROWN, D. and BRENNER, C. (1944), Arch. Neur. छी Psychiat., 52, I.

LEWIS, T., PICKERING, G. W. and ROTHSCHILD, P. (193 I $\vec{p}$ Heart, 16, I.

SEDDON, H. J. and HOLMES, W. (1945), Brit. F. Surg., 32, 38 SUNDERLAND, S. (1945), (a) Arch. Neur. E Psychiat., Chicaga 53,91 .

SUNDERLAND, S. (1945), (b) Arch. Neur. \& Psychiat., Chicag@ 54, 280.

SUNDERLAND. S. (1945), (c) Arch. Neur. $\bullet$ Psychiat., Chicag\%u 54, 283 .

\title{
$\int$ \\ CONFUSIONAL STATES IN ACUTE DISEASE
}

\author{
By J. M. NaISh, M.D., M.R.C.P. \\ Tutor in Medicine, University of Bristol.
}

Many a patient's battle to overcome an acute disease is lost because, failing to stand the strain of the illness, he becomes delirious. The additional burden thrown upon his body by restlessness, fear, and failure to obey those trying to help, is sufficient to tip the balance against him. The problem which such cases present is a common one, and, lying in the no-man's-land between general medicine and psychiatry, does not receive the attention which it needs.

\section{Classical Delirium}

There is nowhere any sharp dividing line between the full-blown picture of severe delirium and the mild nocturnal confusion of thought so frequently found in ill people.

Many patients, particularly the elderly, become confused when their illness is at its height. This confusion and lack of grasp, always at its worst nocturnally, may lead them to get out of bed in the belief that they should be going out to work, or to put their shoes on beneath the sheets to keep their feet warm. They are often shamefaced in the morning and attribute their experiences to a bad dream.

Fully developed delirium leads to well-defined physical and mental changes in these patients, and these should be kept clearly in mind.
The physical manifestations are restlessness, in somnia, incontinence and anorexia ; examination usually shows some pyrexia and tachycardia, aD furred tongue and slurring of the speech.

The mental changes vary from one moment to the next. The changing form of the menta? picture is perhaps the most typical finding in delirium and is due to the extreme suggestibility of delirious people whose moods and behavious are swayed both by their physical surroundings and their attendants. The prevailing delirious mood, however, is one of fear and horror; their speech abounds with talk of struggles, crises ancis bankruptcy. Restless activity and complete ino somnia dominate the picture.

The delirious are not only prone to invent, or t命 elaborate the truth in a broken sort of way, but they misinterpret their present surroundings and instructions. Essentially, this inability to interpret or understand the present has the same roots failure of memory, concentration, and mentas grasp-as the tendency to invent the past. The can only do the simplest and shortest test problems because they cannot hold their brains to the taske? for more than a few moments at a time. It iso true to say, however, that some delirious patients. can, by a superhuman effort of will, achieve mentad clarity when circumstances urgently demand it. 
Yet another characteristic of delirious people is their reference to ideas of persecution. A patient may blame his wife, his children and the corporation for his sleeplessness, though there is no order nor reason in such accusations.

Disorders of sensation and perception occur frequently; visual hallucinations are the most commonly experienced, but occasionally voices are heard or creeping sensations felt beneath the skin.

The classical features of delirium then are, restlessness, insomnia, a fearful mood, confusion of thought and grasp, memory defect, confused paranoid ideas, hallucinations, and a mental state which is liable to change not only from day to day but from hour to hour.

\section{Atypical Forms of Delirium}

\section{(a) Hallucinating}

This form of delirium is, of course, most typical of alcoholic poisoning. The chief features of delirium tremens are visual hallucinations, fear and ceaseless motor activity, but in this as in other intoxications, notably those produced by belladonna or bromide, hallucinations may dominate the picture. Such a state may be difficult to distinguish from the acute onset of psychotic mania.

\section{(b) Amnestic (Korsakow's Syndrome)}

Patients may develop a form of mental disturbance during the course of an acute disease in which, at first sight, mental confusion does not appear conspicuous, and from which the ceaseless motor activity, so typical of most forms of delirium, is absent or slight. Though they appear rational, such patients confabulate, invent fairy tales which are spoken as the truth, confuse the past with the present, have no memory for recent events, and obstinately hold wrong ideas of their position in space. More careful appreciation shows that they have, in fact, a severe defect of memory and a consequent deterioration of intellect. Being really unaware of themselves and their surroundings, they are completely disorientated.

\section{(c) Delirious Stupor}

Many infections, typhoid fever for example, are so overwhelming that the activity of delirium is masked by toxic stupor, which is also the case when acute vitamin deficiencies develop in the course of fevers or gastro-intestinal disturbances.

\section{The Aetiology of Toxic Confusion and Delirium}

No direct pathological cause has been found for the gross disturbances of cerebral function which occur in most intoxications. When the brain or its coverings are affected by an inflammatory process such as encephalitis, meningitis, or an abscess, the cause of mental confusion is not far to seek ; and, when acute vitamin deficiencies produce not only well-defined confusional states but also demonstrable vascular changes and alterations in cell structure within the brain, it may then be said that a specific aetiology has in these cases been discovered. As a rule, however, workers in this field have had to postulate some unknown disturbance of cerebral nutrition or blood supply to cover their ignorance of the real pathology.

One concept has helped us to explain the fundamental similarity between the toxic psychoses produced by different poisons or infections. There is a threshold for toxaemia in each individual over which mental confusion will develop. The noxious dose from some infections and some poisons is obviously greater than from others, but the stage at which mental confusion develops depends primarily on the constitution of the patient. Furthermore, the exact form which a toxic psychosis takes depends far more on the hereditary and psychological make-up of the patient than upon the nature of the toxic process. The psychosis is, therefore, determined both quantitatively and qualitatively by the character of the patient.

Nevertheless, it is true that certain toxaemias give rise more often than not to a particular type of psychosis. Typhoid causes lethargy and a muttering delirium. Streptococcal septicaemia often leads to seeming mental clarity but hallucinations occur.

\section{Confusional States of Specific Aetiology Water Depletion}

This causes intracellular dehydration, a process which probably does not spare the cerebral neurones. Confusion begins to appear when there is a bodily water deficit of about five litres, that is, under temperate climatic conditions after about four days of complete water deprivation. The onset of the full psychotic picture may be sudden, violent reactions occur, and hallucinations are common.

Because people deprived of water suffer from intolerable thirst, it is unlikely that confusional states purely due to dehydration should occur in ordinary practice. Many ill, confused patients are, however, also suffering from a water deficit and this should be made good by pressing fluids by mouth, or if necessary by intravenous infusion of glucose saline.

\section{Salt Depletion}

This lowers the osmotic tension of the extracellular fluids and so leads to extracellular dehydration and interference with cellular nutrition. ஸ) 
Apathy, lassitude and exhaustion, gradually develop and later give way to a stuporose confusional state. Such mental confusion is often seen in patients who have lost large quantities of salt by sweating, vomiting, or diarrhoea, as in pyloric stenosis, ulcerative colitis and Addison's disease.

In many diseases and post-operative states patients suffer from unsuspected salt depletion. This may lead to a mental confusion which interferes with the management of their original disease. If the urine is not unduly dilute, salt depletion should be suspected when the urinary chloride excretion is under $2 \mathrm{gm}$. per litre as estimated by Fantus' simple method. If vomiting or anorexia is present, extra salt must be given by the intravenous infusion of isotonic saline (0.9 gms. $\mathrm{NaCl}$ per $100 \mathrm{cc}$.). In other circumstances the salt may be given by mouth in the form of sodium chloride in cachets.

\section{Alkalosis}

The mental confusion which sometimes occurs in patients suffering from pyloric stenosis is no doubt chiefly attributable to salt deficiency, but similar symptoms may be met with in patients with peptic ulcers who have taken large quantities of alkalis by mouth. The diagnosis must be confirmed biochemically and acid-forming salts (acid sodium phosphate 2 gms. in cachets four-hourly or more frequently) given.

\section{Cerebral Anoxaemia}

This occurs in patients after a severe haemorrhage, an haematemesis for example, after carbon monoxide poisoning, and in patients with congestive heart failure. Hallucinations are not common, but severe mental confưsion, misinterpretation of surroundings, fearful dreams and restlessness, make up the clinical picture. Restlessness, in those whose life depends on adequate rest, may be a symptom very difficult to control and to treat, and may, in fact, be the prime cause of death. As with the anoxaemia of high altitudes, the mental confusion is often tinged with an euphoric and fatuous mood.

Cerebral anoxaemia due to heart failure can rarely be modified unless the cardiac condition improves. In most cases the anoxaemia is due to the stagnation and deoxygenation of blood in the cerebral tissues, but in the presence of pulmonary oedema an anoxic factor may also be present so there is a clear indication for the immediate and thorough administration of oxygen through a B.L.B. mask.

The immediate treatment by blood transfusion, wherever and whenever practicable, of haemorrhage sufficient to cause mental confusion is doubly important because there is a danger that such patients, if left exsanguinated for long, may develop permanent damage to nervous tissue. $\stackrel{\mathbb{Q}}{\mathcal{Q}}$ This happens in post-haemorrhagic amaurosis.

\section{Hypoglycaemia}

Hypoglycaemia, such as occurs after an overdosage of insulin may, before the onset of coma, lead to mental confusion, restlessness, failure of memrry and judgment.

\section{Acute Vitamin Deficiencies}

(a) Cerebral Beri-Beri (Wernicke's Encephalopathy). Since 1938 it has been suspected that $\vec{\omega}$ Wernicke's encephalopathy was due to a nutritional deficiency, probably of thiamine, associated with alcoholic or neoplastic cachexia.

It remained for a large human experiment to prove the case and this was provided by the con- $\mathcal{O}$ ditions under which the Japanese kept Allied. P.o.W.s in the Far East. Thanks to the in- $\vec{A}$ telligence and awareness of imprisoned medical 음 officers, not only was a severe outbreak of en- cephalopathy recognized at once, but the thera- $c$ peutic efficiency of thiamine in these early cases was proved beyond all doubt. The outbreak of $\frac{m}{2}$ cerebral symptoms also coincided with the peak incidence of classical beri-beri amongst the prisoners.

Since the development of cerebral beri-beri was watched carefully from its very outset in these patients, the symptomatology differs somewhat from that of cases previously described in the literature. Early cases were recorded, and recovered patients were able to recall something of $\overrightarrow{\vec{\beta}}$ their sensations during the onset and recovery period. It is worth while then, since this encephalopathy, though not common, may be met with as a complication of many diseases, to recall $\overline{0}$ the cardinal features of cerebral beri-beri, as 3 described by observers in the Singapore camps.

Cerebral beri-beri occurred chiefly in those with severe diarrhoea (which impairs the synthesis and absorption of thiamine from the gut) or in those with febrile condition (in which the body's demand 9 for thiamine is enormously increased). The earliest symptoms were anorexia, apathy and insomnia, followed by nausea and vomiting. $\mathrm{Re}-\mathrm{N}$ covered patients stated that at this stage all sensa- 0 tions were dull and toneless. Later these de- $\tilde{O}$ veloped visual disturbances such as diplopia, $\underset{\omega}{ }$ blurring or failure of vision, and mental changes such as disorientation and amnesia, accompanied 0 perhaps by hallucinations or excitement, but $\Phi$ usually ending in fatal cases with stupor. ? Occasionally in fulminating cases severe mental 0 symptoms developed at the outset. The most frequent physical abnormalities were nystagmus, external rectus fatigue and signs of classical beri- 
beri. Peripheral neuritis was nearly always present. Other clinicians have stressed the frequent finding of pupillary abnormalities in this condition. The classical pathological lesions of cerebral beri-beri were multiple haemorrhages in the corpora mamillaria, around the aqueduct of Sylvius, in the posterior corpora quadrigemina and in the thalamus. Microscopically, these haemorrhages were seen to have come from capillaries irregularly dilated, thickened and deformed. Chromatolysis of ganglion cells and proliferation of the glia occurred in the affected areas.

In clinical practice, cerebral beri-beri may be met with in any condition producing severe diarrhoea, vomiting or cachexia, particularly if accompanied by fever. It is most often seen in severe chronic alcoholism or as a terminal event in patients with carcinoma of the stomach. It does also occur in conditions of better prognosis, such as hyperemesis gravidarum, pernicious anaemia or ulcerative colitis. For reasons not well understood, it may occur as a complication in severe liver disease. Once a fatal disease and now curable, it must be recognized and treated in the earliest stages for the best results. Any patient developing mental confusion and ocular abnormalities in the course of other general diseases, should be treated as a case of cerebral beri-beri, 20-50 mg. of thiamine hydrochloride should be given intramuscularly at once and $20 \mathrm{mg}$. per diem subsequently. Dehydration should be corrected and as appetite returns a diet should be given which contains plenty of animal protein, yeast and Marmite. Patients who develop the Korsakow's syndrome during the course of cerebral beri-beri may be left with a permanent memory defect, and may never regain mental normality.

(b) Nicotinic Acid Deficiency Syndrome. Joliffe et alia (1940) described a syndrome developing in elderly patients ill from a variety of general diseases which was characterized by disorientation, stupor, cog-wheel rigidities of the extremities and the occurrence of uncontrollable grasping and sucking reflexes. The patients improved when treated with $300 \mathrm{mg}$. of nicotinic acid daily intravenously, and many of them recovered, though a similar group treated with thiamine did no better than a control group. The pathological basis of this type of cerebral disturbance has not, so far, been adequately studied. It seems probable, however, that it may be the result of acute nicotinic acid deficiency, just as pellagra is chiefly the result of chronic nicotinic acid deficiency. Certainly, ill patients who become disorientated and develop grasping and sucking reflexes for which no immediate organic cause can be found, should be treated by large doses of nicotinic acid parenterally.
The therapeutic effect should be obvious within two to three days.

Often patients develop symptoms and show signs which are suggestive, but not diagnostic, of acute hypovitaminosis $B$. In view of the risk of permanent sequelae in untreated cases it may be justifiable to treat such doubtful cases with parenteral thiamine and nicotinic acid.

\section{Case Record}

A woman aged $5 \mathrm{I}$ with no previous history of dyspepsia, suffered a moderately severe haematemesis. When seen the next day she did not appear unduly exsanguinated or shocked and was cheerful. Her spleen was palpable about $1 \frac{1}{2}$ in. below the left costal margin. Two days later, her haemoglobin being then 70 per cent. of normal, she became mentally confused, drowsy and finally stuporose. On examination there was generalized muscular rigidity ; no grasping or sucking reflexes were present. Cerebrospinal fluid was normal. On account of these findings, and because a diagnosis of hepatic cirrhosis with bleeding oesophageal varices seemed a possibility, she was given nicotinic acid $100 \mathrm{mg}$. and thiamine hydrochloride Io mg. intramuscularly daily. Within 48 hours she had recovered consciousness, appetite and well-being. Later she successfully underwent an operation for splenectomy during which her cirrhotic liver was seen.

\section{Confusional States due to Specific Poisons Morphia}

Morphia addicts, who are deprived of their drug by an acute illness, often develop great restlessness, insomnia and confusion. Tremors and twitchings are usually present.

\section{Belladonna}

Excitement, pressure of ideas, restlessness, tremors, complex repetitive movements, and hallucinations associated with tachycardia, dilated pupils, a dry mouth and a dry red skin, make a fairly distinct clinical picture. The condition must be treated symptomatically as there is no effective antidote. If restlessness passes into violence, chloroform or ether may be used to control the spasms.

\section{Lead}

Chronic plumbism may lead to a wide variety of mental disturbances which may first appear when an acute disease or carcinomatous metastases cause bony decalcification and consequent liberation of stored lead into the blood stream. Organic neurological signs or convulsions usually occur. The treatment is to give large quantities of 
alkalis, calcium lactate and milk by mouth in an attempt to fix the lead in the bones.

\section{Bromides}

Bromism may lead to mental confusion, intellectual deterioration, memory loss and distant hallucinations. Organic neurological signs, such as dysarthria, depression of deep and superficial reflexes, and tremors may be present. Unless the condition is thought of and an enquiry made into the drugs which a patient has been taking, the mental confusion may be ascribed to some other cause and specific treatment not begun at once, with disastrous permanent results. A blood bromide level of $100 \mathrm{mg}$. per $100 \mathrm{ml}$. or over is diagnostic. The best treatment is to give large quantities of fluids and of sodium chloride by mouth.

\section{Alcohol}

Delirium tremens has been produced experimentally in human volunteers by the daily consumption of a litre of whisky. The occurrence of delirium was not prevented by nutritional supplements or daily injections of thiamine. It was therefore the direct result of alcoholic poisoning. The clinical features are those of classical delirium, but the vivid visual hallucinations and the constant semi-purposeful movements are peculiar. It has always been said that if tachycardia, cardiac dilatation and failure develop during delirium tremens, the prognosis becomes very bad. These are, however, but the cardiac manifestations of hypovitaminosis B and should be treated promptly with thiamine.

\section{Confusional States of Doubtful Aetiology}

Diabetic coma is always and uraemia usually associated with dehydration. The mental confusion which develops in such cases may be due to cellular dehydration.

\section{Confusional States Associated with Organic Intracranial Lesions}

Inflammatory brain lesions in particular are liable to be complicated by acute confusional states. The first consideration in any patient who develops confusion or delirium early in the course of a fever should be to exclude meningitis or other treatable intracranial conditions.

Mental confusion is a particularly troublesome feature of severe head injuries. The temporary abolition of such symptoms by the intravenous injection of hypertonic glucose solution, or the introduction of a saturated solution of magnesium sulphate into the rectum, is evidence that cerebral oedema is their cause. Subdural haematomata often cause fluctuating mental symptoms. Cerebral tumours may present with symptoms of generâे disease and a variety of mental disorders.

\section{Confusional States of Unknown Aetiolog}

As has already been suggested, it is the patient own physical and mental constitution which chiefly determines whether or not a toxic psychosis develops in the course of an acute febrile illness? Advanced age or cerebral atheroma are two of the more obvious constitutional defects predisposing to mental confusion.

Pneumonia, malaria, typhoid, typhus, fut minating exanthemata and the septicaemias ares the most important of the fevers in which deliriung commonly occurs. It may also occur in destrue tive liver disease. Malaria is important as a cause of delirium, because the diagnosis is often missed and life-saving treatment delayed. It should noft really be considered in the same breath as the other fevers in that organic cerebral changes, destructio $\vec{m}$ of neurones in the areas supplied by cerebraf capillaries blocked with cellular debris, are usually found and in that organic neurological disturbances such as convulsions, aphasia or hemiplegia occue

Drugs in common use today which may give rise idiosyncratically to confusional states are the sulphonamides.

\section{The General Treatment of Confusionatad States}

The treatment of delirium is vital because the patient's ability to fight his original disease depend so much upon his getting over the mental dis turbance without too great a loss of energy. Thy general practitioner or physician sees such case: and has to treat them, but the textbooks to which he has access give little advice on the subject? Often there is not much which can be done in suct cases, but there is always a great deal which ougle not to be done. Some treatments may be trieg without harm, others must be abjured completel

\section{Principles of Treatment}

I. Seek out and treat, if present, any conditiog such as salt depletion or hypovitaminosis which are known to cause mental confusion.

2. Treat the underlying disease adequately.

3. The patient should be nursed and manageep by those skilled in managing the unmanageable Care and tact reduce a patient's restlessness, but silly interference or attempts to bully him will produce violent reactions. Those who are know to irritate him when sane should not be allowed approach him when delirious.

4. Make the patient's surroundings simple and easy to understand. The wards of a genera hospital with their bustle and noise are unsuitable A quiet, partially darkened room, where he should 
not be alone, is the ideal. Once the patient has been moved to suitable surroundings, do not move him again or in any way ask his confused brain to understand any but the simplest things.

5. Hydrotherapy. Great restlessness may be lessened by the application of wet packs or by immersion in a bath. The former is generally better because it is less disturbing.

6. Diet. Readily assimilable carbohydrate foods, preferably in fluid or semifluid form, are the easiest to give. The caloric intake should be about $2,500 \mathrm{C}$. daily. If such high carbohydrate feeding has to be continued for more than three days, or if the patient has been starved previously, thiamine and nicotinic acid should be given parenterally as prophylaxis.

7. Drugs. The less of these the better. Give them not at all or infrequently. If you have to use them, see that the dose is adequate, the aim being to produce quietness and sleep. Hyoscine hydro- bromide $0.5 \mathrm{mg}$. is not too much. The elderly and sufferers from delirium tremens respond well to hyoscine. Paraldehyde $12-20 \mathrm{ml}$. is safe. Morphia in doses of 20-30 mg. may be given if the co-existing disease provides no contraindication. It should be remembered, however, that certain patients do not tolerate morphia or hyoscine.

When confronted with a patient who becomes mentally confused or delirious during the course of another illness, the first aim of the physician should be to exclude or treat organic cerebral disease, gross alterations in the cell environment, deficiency states, or drug intoxications. Only then should he regard the case as one of toxic psychosis to be treated symptomatically.

\section{BIBLIOGRAPHY}

CURRAN, D., Encycl. Med. Practice, 10, 316.

DE WARDENER, H. F., and LENNOX, B. (1947), Lancet, I, II. JOLIFFE, N. et alia (1940), F. Am. Med. Assn., 114, 307.

SPILLANE, J. D. (1946), "Nutritional Disorders of the Nervous System.' Edinburgh. Livingstone.

\title{
SPEECH ITERATIONS
}

\author{
('Ting a Ling' Phenomenon)* \\ By Macdonald Critchley, M.D., F.R.C.P. \\ Neurologist, King's College Hospital; Physician, National Hospital, Queen Square.
}

Like an Englishman abroad who rings the changes in his conversation on the few phrases of which he is the master, so in the same way: we meet patients who reiterate certain words, phrases or sentences to the exclusion of all others. Thereby we are reminded not only of our traveller, but of some animal cries and infantile babbling-. monotonous repetitions which constitute the whole of the subject's vocalization.

The circumstances under which we encounter these speech iterations are very diverse; some of the cases are frankly psychotic, others are neurological problems. Sometimes they obviously form an aphasic disturbance- a disorder of language. In other cases the defect is one of articulation or speaking. At other times it is difficult to decide, and possibly a disorder both of speech and of speaking coexists. With others again the defect is plainly the result of a thought disorder upon a conceptual plane higher than the zone of language.

Years ago Gairdner applied the term 'barrelorganisms' to all these various kinds of speech

* Being a paper read at La Salpêtrière, Paris, on November I 2 th, 1947. iterations. The term is not a very satisfactory one for the recurrent vocalization is neither a melody nor a theme. More often it is merely a phrase, or maybe a single word. One might, perhaps, use the term ' ting a ling phenomenon,' after the music-hall song which was familiar last century. $†$

\footnotetext{
$\uparrow$ She only answered ' ting a ling' To all that I could say.

She seemed to live on 'ting a ling' By night as well as day.

When I asked her if she'd marry me All that she could say

Was 'ting a ling a ling ting, Ting a ling a ling ting

Ting a ling a lins, ting tay.'
}

English folk music embodies a number of meaningless phrases of dubious etymology. Ranging from the oldtime 'Hey nonny nonny ney' and ' Fol-de-rol,' etc., we come to the 'Tick-a-tang'. and the 'Tararaboomdeay' of two generations ago, the ' Yip I addy I ay I ay' and the 'Hitchy-koo' of the first war and the various nonsense syllables of the Hill Billy songs we hear today. Perhaps these are melodious phrases easy to sing; more probably they represent broken-down sense words or dilapidated speech. 